\title{
Baseline plasma fibrinolysis and its correlation with clinical manifestations in patients with Raynaud's phenomenon
}

\author{
C S Lau, M McLaren, I Mackay, J J F Belch
}

\begin{abstract}
Objectives-(1) To assess if patients with various forms of Raynaud's phenomenon (RP) have abnormal plasma fibrinolysis that may contribute to diminished digital blood flow; (2) to assess whether patients with RP with evidence of endothelial damage have abnormal plasma fibrinolysis; (3) to determine the clinical relevance of abnormalities, if any, in plasma fibrinolysis in patients with $R P$.

Methods-One hundred and sixty eight patients with significant $\mathbf{R P}$ were studied-46 had primary Raynaud's disease (RD), 32 had suspected Raynaud's syndrome secondary to an undifferentiated connective tissue disorder (undifferentiated CTD), 25 had Raynaud's syndrome associated with atherosclerosis (athero RS), and 65 had an underlying connective tissue disease (CTD RS). All attended in the morning after a low fat light breakfast. After a clinical history was obtained, venous blood samples were collected without stasis for assays of plasma fibrinolysis and factor VIII von Willebrand factor antigen (fVIII vWF Ag). Results were compared with those obtained from normal subjects matched for sex and age. As patients with athero RS were significantly older than the other patients with Raynaud's phenomenon, two groups of control subjects were recruited-namely, 'old' and 'young' control subjects.
\end{abstract}

Results-Patients with CTD RS and athero RS had higher concentrations of fVIII vWF Ag (CTD RS median 174.5 range $(45-370) \% \quad v \quad 100 \quad(38-202) \%$, p<0.001; athero RS $182.5(100-240) \% v 100$ $(50-158) \%$, p<0.001). Both had raised fibrinogen (CTD RS 3.25 (1.9-6.8) g/l v 2.4 $(1 \cdot 2-4 \cdot 2) \quad g / 1, \quad p<0 \cdot 001$;athero RS 3.4

University Department of Medicine,

Ninewells Hospital and

Medical School,

Dundee DD1 9SY

C S Lau

M McLaren

I Mackay

J J F Belch

Correspondence to: Dr C S Lau, University Department of Medicine,

Queen Mary Hospital,

Pokfulam Road,

Hong Kong.

Accepted for publication

28 January 1993 those who had RP all year and those who had RP in the winter only, those with RP of the hands only and of hands and feet, or those with and without digital ulcers.

Conclusion-Diminished plasma fibrinolysis is found in patients likely to have endothelial damage (CTD RS and athero RS). These changes are probably a consequence rather than a cause of the disease.

(Ann Rheum Dis 1993; 52: 443-448)

Raynaud's phenomenon ( $R P$ ) was first defined by Maurice Raynaud in 1862 as episodic digital ischaemia provoked by cold and emotion. ${ }^{1}$ It is a common condition affecting $5 \%-10 \%$ of the population and is nine times more common in women than in men. Although RP may be benign when it is not associated with an underlying condition (primary Raynaud's disease (RD)), it can still significantly affect a patient's lifestyle. When RP is associated with an underlying disorder (secondary Raynaud's syndrome (RS)), the viability of the digits may be threatened. Recently, a third subdivision of patients with RP has been delineated-namely, suspected Raynaud's syndrome secondary to an undifferentiated connective tissue disease (undifferentiated CTD). This group of patients often presents with severe Raynaud's symptoms and clinical features that are suggestive but not diagnostic of CTD.

Treatment for RP has been unsatisfactory as little was known about its true aetiology until recently. As well as dysfunction of nervous control of blood vessels ${ }^{2-4}$ patients with $\mathrm{RP}$ may have abnormal blood rheology and coagulation. ${ }^{56}$ Hyperviscosity and hyperfibrinogenaemia have been implicated in its pathogenesis when linked to systemic sclerosis. ${ }^{78}$ These changes may be related to a deficiency in the fibrinolytic system. ${ }^{10}$ Although there is general agreement that patients with RS secondary to a CTD, especially systemic sclerosis, have diminished plasma fibrinolysis, there is no agreement regarding the aetiological role of fibrinolysis in primary $\mathrm{RD}$. Hyperfibrinogenaemia and reduced fibrinolytic activity have been documented in patients with primary $\mathrm{RD}$ by some authors ${ }^{7-9}$ but not others. ${ }^{10}$ Holland et $a l^{10}$ suggested that this was due to poor selection of patients and that carefully characterised patients with primary $\mathrm{RD}$ have normal fibrinolysis. 
As well as this controversy, fibrinolysis in other forms of RP has not been extensively investigated. Previous studies have shown raised factor VIII von Willebrand factor antigen (fVIII vWF Ag) concentrations in plasma in patients with $\mathrm{RS}$ and vascular damage. ${ }^{11}$ As fibrinolysis is largely a function of endothelial cells, whether patients with damaged endothelium and raised fVIII vWF Ag have abnormal fibrinolysis has not been documented previously. Furthermore, the clinical relevance of such abnormalities, if any, has not been studied. For these reasons, we have studied baseline plasma fibrinolysis and fVIII vWF Ag in patients with primary RD, undifferentiated CTD, and different forms of secondary RS. To clarify whether any abnormalities detected were related to the vasospasm itself or to the underlying disease, in each case a careful clinical history was also obtained followed by a clinical examination. A proportion of the patients were issued with diary cards to record frequency and duration of attacks of vasospasm.

\section{Subjects and methods}

PATIENTS AND CONTROLS

Patients were recruited from an outpatient clinic during the winter months. All were referred by their general practitioners because of severe Raynaud's symptoms that had failed to respond to conservative treatment. Patients who were taking medication for their Raynaud's condition were asked to stop for at least two weeks before entry to the study. All gave written informed consent. Healthy subjects matched for age, sex, and smoking were also studied.

\section{CLINICAL HISTORY AND EXAMINATION}

All patients were interviewed by a medical practitioner and a detailed history of their Raynaud's symptoms was obtained. This included age of onset and duration of RP; family history of RP; and associated features suggestive of an underlying CTD - namely, arthralgia, myalgia, sicca syndrome, photosensitivity, tightening of the skin of the fingers or face etc. Patients were also asked if they had previous occupational exposure to vibrating tools. As a guide to the severity of Raynaud's symptoms, they were asked whether their vasospastic attacks occurred in winter only or in both winter and summer, as well as whether one hand or both hands, and feet were affected.

A medical examination was also carried out and particular attention was paid to the presence of digital ulcers as well as features of obstructive vascular disease, rheumatoid arthritis, and other connective tissue diseases. A nailfold capillary microscopy examination was also performed.

DIARY ASSESSMENT OF SEVERITY OF RAYNAUD'S SYMPTOMS

Some patients were provided with pocket size diary cards with detailed instructions to record all attacks of Raynaud's phenomenon over a two week period. An attack was defined as white discoloration of one or more fingers, with or without paraesthesia, precipitated by cold, emotion, or a sudden drop in the surrounding temperature. The duration of the attack was also measured (in minutes) and was defined as the time elapsing between the start of an attack to the disappearance of blanching in the finger(s). The total number and duration of all attacks of Raynaud's phenomenon that occurred during the two week period were calculated.

ROUTINE BLOOD TEST

Routine blood haematology, biochemistry (including renal function), and immunology were carried out on all patients as part of screening for CTD.

ASSAYS OF PLASMA FIBRINOLYSIS AND FACTOR VIII VON WILLEBRAND FACTOR ANTIGEN All subjects attended between 0900 and 1000 hours in the morning after a standard low fat light breakfast that comprised one slice of toast without butter and a glass of orange juice. Patients were asked to refrain from cigarette smoking from the previous evening. All rested for at least 30 minutes before venepuncture. Blood samples were obtained without stasis with a gauge 19 butterfly at least 30 seconds after release of the tourniquet. The following assays were performed:

Factors involved in the fibrinolytic pathway

Fibrinogen, a substrate for fibrin that is involved in clot formation, was measured with the Automated Coagulation Laboratory nephelometric centrifugal analyser (Instrumentation Laboratory) by the method of Clauss. ${ }^{12}$

Fibrinopeptide $A$, a degradation product of fibrinogen by thrombin, was measured with a competitive two step enzyme linked immunosorbent assay (Boehringer Mannheim).

Plasminogen, the precursor of plasmin that lyses fibrin, was determined with a chromogenic substrate assay (Instrumentation Laboratory). This assay is not affected by raised plasma concentrations of fibrin degradation products and fibrinogen.

Plasminogen activator activity was determined by fibrin plate lysis area. ${ }^{13}$

Product of endothelial damage

Plasma fVIII $v W F A g$, an endothelial product released after vascular damage, was assayed with the Laurell rocket technique. ${ }^{14}$

\section{STATISTICAL ANALYSIS}

The Mann-Whitney U test and Spearman's rank correlation test were used as appropriate. A p value of $<0.05$ was considered significant. Results of assays are expressed as median (range).

\section{Results}

PATIENTS AND CONTROLS

One hundred and sixty eight patients were recruited. Forty six had primary RD, 32 had 
Table 1 Demographic details of subjects studied and summary of the patients' histories of Raynaud's phenomenon

\begin{tabular}{lllllll}
\hline & Athero $R S$ & CTD RS & Undifferentiated & $R D$ & Old controls & Young controls \\
\hline No & & & $C T D$ & & \\
Age (y; mean) (SD) & 25 & 65 & 32 & 46 & 26 & 48 \\
Male:female & $63 \cdot 2(10 \cdot 5)$ & $46 \cdot 4(12 \cdot 5)$ & $42 \cdot 4(13 \cdot 3)$ & $31 \cdot 3(12 \cdot 4)$ & $58 \cdot 6(10 \cdot 4)$ & $39 \cdot 9(8 \cdot 5)$ \\
Smokers:non-smokers & $11: 14$ & $11: 54$ & $7: 25$ & $4: 42$ & $12: 14$ & $6: 42$ \\
Duration of RP (y; mean) (SD) & $8: 17$ & $28: 37$ & $19: 13$ & $18: 28$ & $10: 16$ & $22: 26$ \\
Family history (yes:no) & $6 \cdot 5(7 \cdot 3)$ & $9 \cdot 7(7 \cdot 0)$ & $8 \cdot 6(7 \cdot 9)$ & $7 \cdot 2(6 \cdot 4)$ & - & - \\
Season (winter only:all year) & $6: 19$ & $6: 59$ & $13: 19$ & $18: 28$ & - & - \\
Digital ulcers (yes:no) & $9: 16$ & $10: 55$ & $10: 22$ & $19: 27$ & - & - \\
Involvement of hands only:hands and feet & $4: 21$ & $43: 22$ & $2: 30$ & $0: 46$ & - & - \\
\hline
\end{tabular}

Athero RS=Raynaud's syndrome associated with atherosclerosis; CTD RS=Raynaud's syndrome with underlying connective tissue disease; undifferentiated CTD=Raynaud's syndrome secondary to an undifferentiated connective tissue disorder; RD=primary Raynaud's disease.

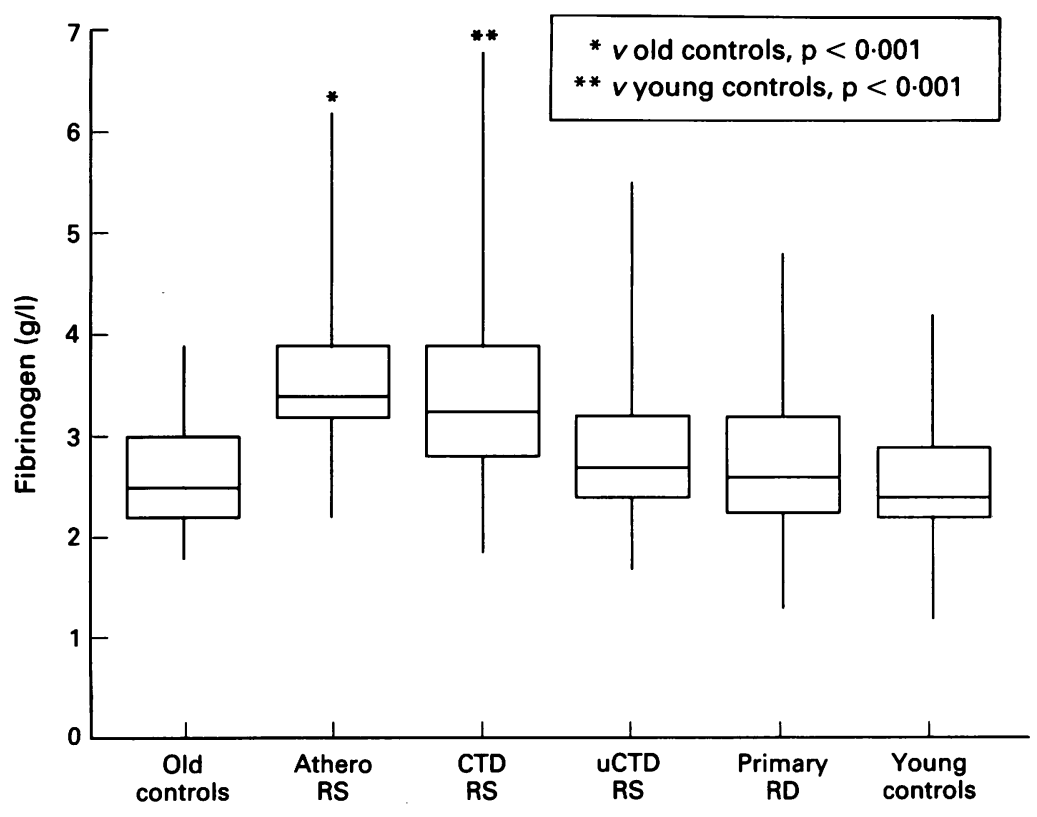

Figure 1 Plasma fibrinogen concentrations in patients with atherosclerotic Raynaud's syndrome (athero RS), Raynaud's syndrome associated with connective tissue disease (CTD RS), undifferentiated connective tissue disorder and secondary Raynaud's syndrome ( $u C T D R S)$, primary Raynaud's disease (RD), and old and young control subjects. Statistical analysis by Mann-Whitney $U$ test. Results are in median (range); interquartile range boxed.

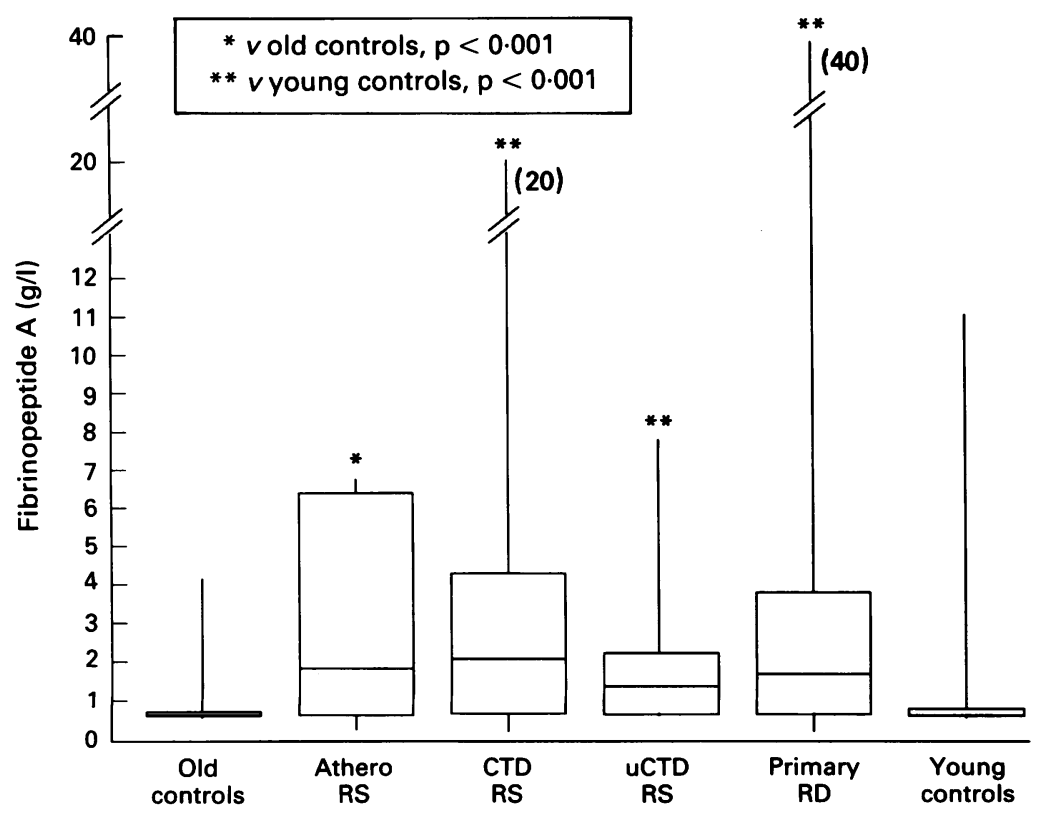

Figure 2 Plasma fibrinopeptide $A$ concentrations in patients with atherosclerotic Raynaud's syndrome (athero RS), Raynaud's syndrome associated with connective tissue disease (CTD RS), undifferentiated connective tissue disorder and secondary Raynaud's syndrome ( $u C T D R S$ ), primary Raynaud's disease (RD), and old and young control subjects. Statistical analysis by Mann-Whitney $U$ test. Results are in median (range); interquartile range boxed. undifferentiated CTD, 25 had RS associated with atherosclerosis (athero RS), and 65 had an associated connective tissue disease (CTD RS). Of those with CTD RS 42 had systemic sclerosis, 20 had systemic lupus erythematosus, two had rheumatoid arthritis, and one had vasculitis of unknown origin. Table 1 shows the demographic details of these patients and a summary of their history of RP. Patients were said to have primary $\mathrm{RD}$ if they complained of digital vasospasm but had no other features suggestive of an underlying condition and had a negative immunology screen. Patients were diagnosed as having undifferentiated CTD if they complained of features suggestive but not diagnostic of a CTD as well as intense digital vasospasm. All patients with CTD RS presented with features that fulfilled the American Rheumatism Association diagnostic criteria for the appropriate condition. ${ }^{15-17}$ Patients with athero RS had other features of peripheral vascular disease such as calf claudication pain as well as severe Raynaud's symptoms and none had any features of a CTD. Also, none of these patients gave a history of occupational exposure to vibration. All had an ankle:brachial pressure ratio of $<0 \cdot 85$. They also all had low digital blood pressure as measured by Doppler flow despite the absence of Raynaud's phenomenon in a warm environment.

As patients with athero RS were significantly older than the other patients with Raynaud's phenomenon, two groups of control subjects, old and young, were recruited (table 1). Results obtained from patients with athero RS were compared with those from the old control subjects whereas results obtained from the other groups of patients were compared with those obtained from the young control subjects.

\section{BASELINE PLASMA FIBRINOLYSIS}

Fibrinogen

Patients with athero and CTD RS had significantly higher plasma fibrinogen concentrations when compared with control subjects (athero RS $v$ old controls median $3 \cdot 4$ range $(2 \cdot 2-6 \cdot 2)$ $\mathrm{g} / 1$ v $2.5(1.8-3.9) \mathrm{g} / \mathrm{l}, \mathrm{p}<0.001$;CTD RS $v$ young controls $3.25(1.9-6.8)$ g/l $v e r 4$ $(1 \cdot 2-4 \cdot 2) \mathrm{g} / \mathrm{l}, \mathrm{p}<0.001)$. There were no significant differences in plasma fibrinogen concentrations between patients with undifferentiated CTD and primary $\mathrm{RD}$ and the young control subjects (fig 1 ). 


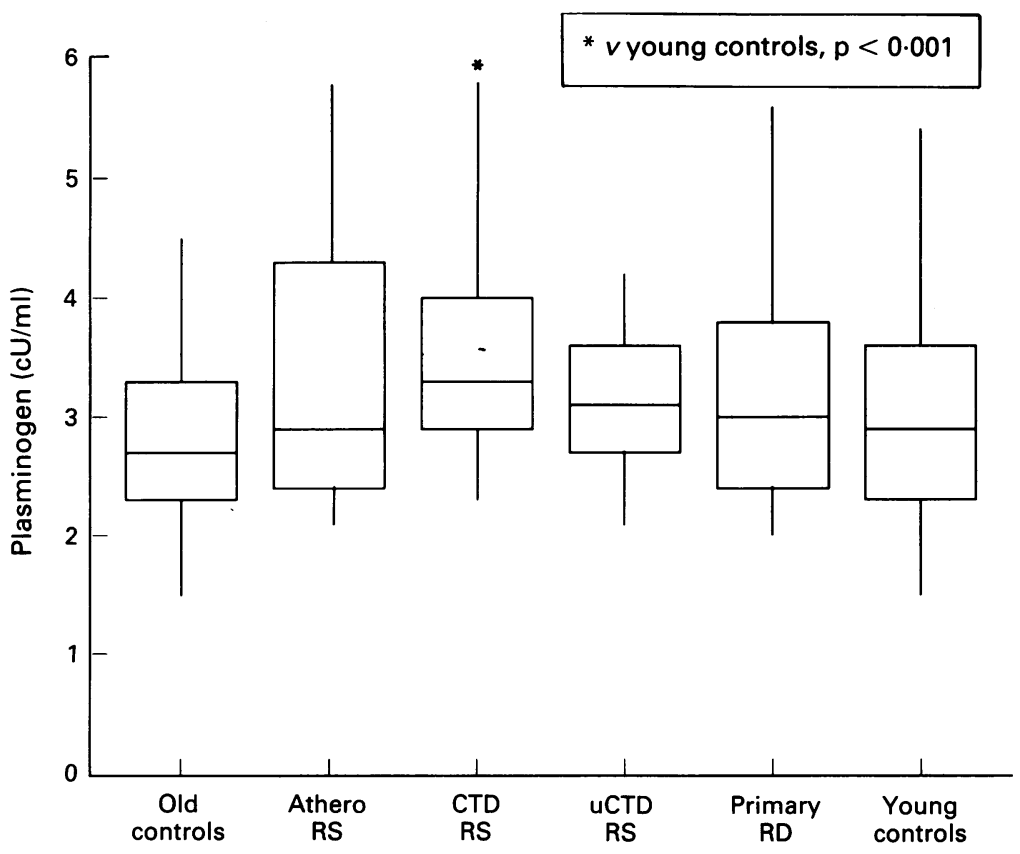

Figure 3 Plasma plasminogen levels in patients with atherosclerotic Raynaud's syndrome (athero RS), Raynaud's syndrome associated with connective tissue disease (CTD RS), undifferentiated connective tissue disorder and secondary Raynaud's syndrome ( $u C T D$ $R S)$, primary Raynaud's disease (RD), and old and young control subjects. Statistical analysis by Mann-Whitney $U$ test. Results are in median (range); interquartile range boxed.

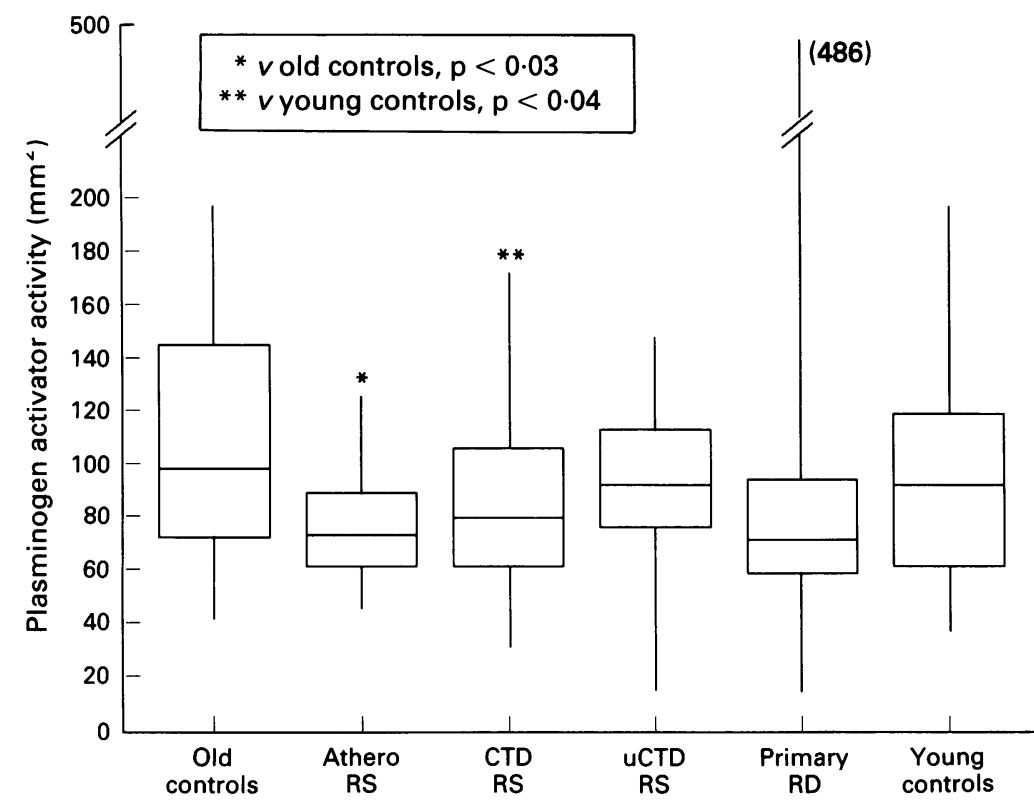

Figure 4 Plasminogen activator activity in patients with atherosclerotic Raynaud's syndrome (athero RS), Raynaud's syndrome associated with connective tissue disease (CTD RS), undifferentiated connective tissue disorder and secondary Raynaud's syndrome ( $u C T D R S)$, primary Raynaud's disease (RD), and old and young control subjects.

Statistical analysis by Mann-Whitney $U$ test. Results are in median (range); interquartile range boxed.
$(2 \cdot 3-5 \cdot 8) \quad v \quad \mathrm{cU} / \mathrm{ml} \quad 2 \cdot 9 \quad(1 \cdot 5-5 \cdot 4) \quad \mathrm{cU} / \mathrm{ml}$, $\mathrm{p}<0.001)$. No significant differences in plasminogen activity was found between patients with athero RS and the old control subjects and those with undifferentiated CTD and primary $\mathrm{RD}$ and the young control subjects (fig 3 ).

Plasminogen activator activity

Plasminogen activator activity was significantly lower in patients with athero RS and patients with CTD RS compared with control subjects (athero RS $v$ old controls 73 (45-125) $\mathrm{mm}^{2} v$ 98 (41-197) $\mathrm{mm}^{2} \mathrm{p}<0.03$;CTD RS $v$ young controls 79.5 (31-172) $\mathrm{mm}^{2} v 92$ (37-197) $\left.\mathrm{mm}^{2}, \mathrm{p}<0 \cdot 04\right)$. There were no significant differences in plasminogen activator activity between patients with undifferentiated CTD and primary $\mathrm{RD}$ and the young control subjects (fig 4 ).

\section{FACTOR VIII VON WILLEBRAND FACTOR}

ANTIGEN

Patients with athero RS and CTD RS had significantly higher concentrations of fVIII $\mathrm{vWF} \mathrm{Ag}$ in plasma compared with control subjects (athero RS $v$ old controls 182.5 $(100-240) \%$ v $100(50-158) \%, \mathrm{p}<0.001$;CTD RS $v$ young controls $174.5(45-370) \% v 100$ $(38-202) \%, p<0 \cdot 001)$. There were no significant differences in plasma fVIII vWF Ag concentrations between patients with undifferentiated CTD and primary $R D$ and young control subjects (fig 5 ).

CORRELATION BETWEEN PLASMA FIBRINOLYSIS AND THE SEVERITY OF ATTACKS OF RAYNAUD'S PHENOMENON

Within each patient group, no significant differences occurred in any measured variables between those who complained of Raynaud's phenomenon all year and those with symptoms in the winter only and those who complained of Raynaud's phenomenon of the hands only and of hands and feet. Of the patients with CTD RS, 43 had one or more digital ulcers and 22 had none. There were no significant differences in plasma concentrations of fVIII vWF Ag and fibrinolysis between these two subgroups of patients.

CORRELATION BETWEEN PLASMA FIBRINOLYSIS AND DIARY RECORDING OF ATTACKS OF RAYNAUD'S PHENOMENON

The first 26 patients recruited into this study (12 with RS associated with systemic sclerosis, eight with undifferentiated CTD, and six with primary $\mathrm{RD}$ ) completed a two week diary recording of the total number and duration of attacks of Raynaud's phenomenon. No significant correlation occurred between severity of Raynaud's symptoms and plasma fibrinolysis (table 2). $\mathrm{g} / \mathrm{l}, 1 \cdot 4(0 \cdot 6-6 \cdot 8) \mathrm{g} / \mathrm{l}, 1 \cdot 7(0 \cdot 3-40) \mathrm{g} / \mathrm{l}$, respectively $v 0.62(0.5-11) \mathrm{g} / \mathrm{l}$, all $\mathrm{p}<0.001)$ (fig 2$)$

Plasminogen

Patients with CTD RS had significantly higher plasma plasminogen activity compared with control subjects (CTD RS $v$ young controls $3 \cdot 3$

\section{Discussion}

During the formation of a blood clot after injury to a blood vessel, fibrinogen is converted 


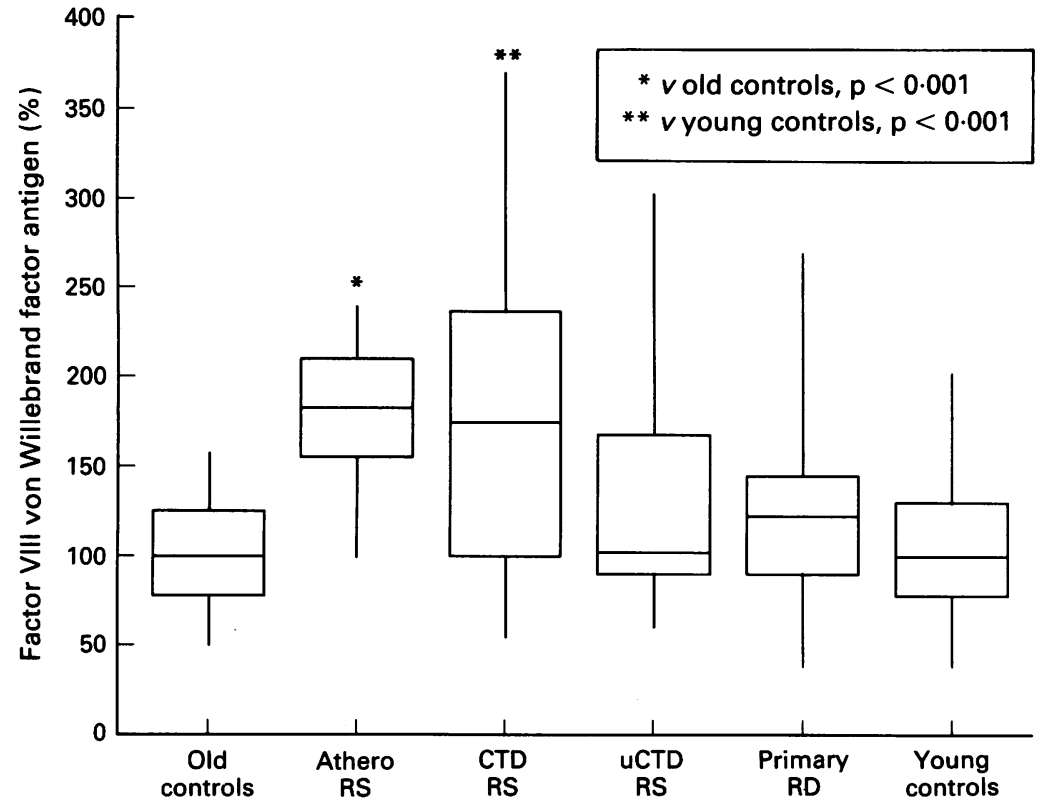

Figure 5 Plasma factor VIII von Willebrand factor antigen levels in patients with atherosclerotic Raynaud's syndrome (athero RS), Raynaud's syndrome associated with connective tissue disease (CTD RS), undifferentiated connective tissue disorder and secondary Raynaud's syndrome ( $u C T D R S)$, primary Raynaud's disease (RD), and old and young control subjects. Statistical analysis by Mann-Whitney $U$ test. Results are in median (range); interquartile range boxed.

Table 2 Correlation between baseline plasma fibrinolysis and diary recording of Raynaud's attacks (Spearman's rank correlation)

\begin{tabular}{lcl}
\hline & $\begin{array}{l}\text { Total number of Raynaud's } \\
\text { attacks in two weeks } \\
r(p \text { value })\end{array}$ & $\begin{array}{l}\text { Total duration of Raynaud's } \\
\text { attacks in two weeks } \\
r(p \text { value })\end{array}$ \\
\hline Fibrinogen & $0.36(0 \cdot 14)$ & $0 \cdot 27(0.26)$ \\
Plasminogen & $-0.18(0 \cdot 47)$ & $-0.05(0.83)$ \\
Plasminogen activator activity & $0.07(0.77)$ & $-0 \cdot 12(0.63)$ \\
\hline
\end{tabular}

into fibrin where its main function is to strengthen the clot. Once haemostasis is achieved excessive deposition of fibrin is prevented by the fibrinolytic system, which is also responsible for the removal of inappropriately formed fibrin. Under such a system the insoluble fibrin is degraded into the soluble fibrin degradation products by the action of the protease plasmin. Plasmin is produced, when required, by cleavage of its inactive precursor plasminogen and the rate of this reaction is determined by the relative proportions of activators and inhibitors of fibrinolysis. Diminished plasma fibrinolysis impedes blood flow and has been shown to be a major mechanism of thrombotic vascular disease. ${ }^{18} \mathrm{~A}$ defective fibrinolytic system may also be of aetiological importance in patients with RP. ${ }^{7-10}$ Treatment of RP with fibrinolytic agents has been tried and was suggested to be of value. ${ }^{19-21}$

To our knowledge, this is the largest study of plasma fibrinolysis in RP and hopefully resolves some of the published conflicts. Firstly, we have confirmed previous studies showing that patients with CTD RS have reduced plasma fibrinolysis. Our patients had raised fibrinogen and plasminogen and reduced plasminogen activator activity. Similar results were found in patients with athero RS suggesting that abnormal fibrinolysis may also have a role in either the aetiology or propagation of disease in this group of patients. These data are important as atherosclerosis is a common cause of secondary RS in patients first presenting at the age of 60 years or older. ${ }^{22}$ It is now known that the endothelium is an important source of plasminogen activators. ${ }^{23}$ Plasminogen activator release is reduced if the endothelial cells are damaged. Our study also confirms that patients with primary $\mathrm{RD}$ and undifferentiated CTD, diagnosed after careful evaluation of their Raynaud's and associated symptoms, have normal overall plasma fibrinolysis with normal fibrinogen, plasminogen, and plasminogen activator activity. Therapeutically, it is important to know that patients with $R P$ not associated with an underlying condition have normal plasma fibrinolysis. Such a finding suggests that these patients are unlikely to respond to the use of fibrinolytic agents as shown by Jayson et al, ${ }^{21}$ especially in view of the fact that presently available fibrinolytic agents are associated with a high incidence of side effects.

Patients with primary $\mathrm{RD}$ and undifferentiated CTD were both found to have raised concentrations of fibrinopeptide A. This was also the case in patients with athero RS and CTD RS. As fibrinopeptide A is a breakdown product of fibrinogen, ${ }^{24}$ we wonder if this phenomenon reflects a tendency for patients with primary $\mathrm{RD}$ and undifferentiated CTD to develop hyperfibrinogenaemia which is, at the time of study, controlled by fibrinolysis. This may explain some of the controversies from earlier studies. Some of these patients may eventually develop an underlying disorder when fibrinolysis becomes inadequate showing that a careful characterisation at the time of study of $\mathrm{RD}$ does not necessarily exclude eventual progression of disease.

The cause of reduced fibrinolysis in our patients with athero RS and CTD RS is likely to be related to endothelial damage secondary to the underlying condition rather than as a direct consequence of vasospasm. Both groups of patients were shown to have raised concentration of fVIII vWF Ag, an endothelial product that is released after damage to blood vessels. Patients with primary $R D$ and undifferentiated CTD had normal plasma fVIII vWF Ag and fibrinolytic activity. That abnormal fibrinolysis is not directly related to vasospasm is further supported by the finding that plasma fibrinolysis does not correlate with severity of symptoms.

In conclusion, diminished plasma fibrinolysis is found in patients with secondary RS (athero RS and CTD RS). This may be secondary to endothelial damage. These changes are probably related to the underlying condition rather than vasospasm as shown by their lack of correlation with frequency and duration of vasospasm. Nevertheless, whether cause or consequence, reduced fibrinolytic activity is likely to aggravate a condition in which blood flow has already been diminished by intense vasospasm.

Two of us (JB and CL) are in receipt of grants from the Oliver Bird Fund and Scottish Health Endowment Research Trust. We thank Ms H Chik and Ms J Lee for their secretarial assistance. 
1 Raynaud M. On local asphyxia and symmetrical gangrene of the extremities and new researches on the nature and treatment of local asphyxia of the extremities. Selected monographs, Vol 121, translated by T Barlow, New Sydenham Society, London, 1888.

2 Freedman R R, Sabharal S C, Desai N, et al. Increased alpha-adrenergic responsiveness in idiopathic Raynaud's disease. Arthritis Rheum 1989; 32: 61-5.

3 Brotzu G, Falchi S, Mannu B, et al. The importance of presynaptic beta receptors in Raynaud's disease. $\mathcal{F}$ Vasc presynaptic beta recep
Surg 1989; 9: 767-71.

4 Olsen N, Petring OU. Vibration elicited vasoconstrictor reflex in Raynaud's phenomenon. Br f Ind Med 1988; 45: 413-19.

5 Lau C S, Bridges A R, Muir A, et al. Further evidence of increased polymorphonuclear cell activity in patients with Raynaud's phenomenon. $B r \mathcal{F}$ Rheumatol 1992; 31: 375-80.

6 Belch J J F, McLaren M, Anderson J, et al. Increased prostacyclin metabolites and decreased red cell deformability in patients with systemic sclerosis and Raynaud's syndrome. Prostaglandins, Leukotrienes and Medicine 1985; 17: 1

7 Pringle R, Walder D N, Weaver J P A. Blood viscosity and Raynaud's disease. Lancet 1965; i: 1086-88.

8 Goyle K B, Dormandy F L. Abnormal blood viscosity in patients with Raynaud's phenomenon. Lancet 1976; i: $1317-18$.

9 Cunliffe W J, Menson I S. Blood fibrinolytic activity in diseases of small blood vessels and the effect of low molecular weight dextran. $\mathrm{Br} \mathcal{f}$ Dermatol 1969; 81: $220-5$

10 Holland C D, Jayson M I V. Venous blood fibrinolysis and fibrinolytic potential in primary Raynaud's phenomenon and systemic sclerosis associated Raynaud's phenomenon. In: Black C M, Myers A R, eds. Progressive systemic sclerosis. New York: Gower, 1985: 267-73.

11 Belch J J F, Zoma A A, Richards I M, et al. Vascular damage and factor VIII related antigen in the rheumatic diseases. Rheumatol Int 1987; 7: 107-11.
12 Clauss A Gernnungs physiologische Schnell method zur Bestimmung des Fibrinogens. Acta Haematol 1957; 17: 237-51.

13 Kluft C, Brakman P, Veldhuyzen-Stalk E C. Screening of the fibrinolytic activity in plasma euglobulin fractions on the fibrin plate. In: Davidson J F, Samama M M Desnoyers $\mathrm{P} C$, eds. Progress in chemical fibrinolysis and thrombosis. Vol 2 . New York: Raven Press, 1976; 57-65.

14 Laurell C B. Electroimmunoassay. Scand $\mathcal{f}$ Clin Lab Invest Suppl 1972; 124: 21-6.

15 Masi A T, Rodlan G P, Medeger T A, et al. Preliminary criteria for the classification of systemic sclerosis (scleroderma). Arthritis Rheum 1980; 23: 581-90.

16 Tan E M, Cohen A S, Fries J F. The 1982 revised criteria for the classification of systemic lupus erythematosus. Arthritis Rheum 1982; 25: 1271-7

17 Arnett F C, Edworthy S M, Bloch D A, et al. The American Rheumatism Association 1987 revised criteria for the classification of rheumatoid arthritis. Arthritis Rheum 1988; 31: 315-24.

18 Nilsson TK, Johnson O. The extrinsic fibrinolytic system in survivors of myocardial infarction. Thromb Res 1987; 48: $621-30$.

19 Fearnley G R, Chakrabarti R. Phenformin and ethyloestrenol for Raynaud's disease. Lancet 1969; i: 906-7.

20 Jarrett P E M, Morland M, Browse N L. Treatment of Raynaud's phenomenon by fibrinolytic enhancement. Raynaud's phenoment

21 Jayson M I V, Holland C D, Keegan A, et al. A controlled study of stanozolol in primary Raynaud's phenomeno and systemic sclerosis. Ann Rheum Dis 1991; 50: 41-7.

22 Friedman E I, Taylor L M, Porter J M. Late onset Raynaud's syndrome: Diagnostic and therapeutic considerations. Geriatrics 1988; 43: 59-70.

23 Bachman F, Kruithof E K O. Tissue plasminogen activator: Chemical and physiological aspects. Semin Thromb Hemost 1984; 10: 6-17.

24 Marder V J, Schulman N R, Carroll W R. High molecula weight derivatives of human fibrinogen produced by plasmin. F Biol Chem 1969; 244: 2111-19.
D 